University of Nebraska - Lincoln

DigitalCommons@University of Nebraska - Lincoln

\title{
Evaluation of three experimental bovine viral diarrhea virus killed vaccines adjuvanted with combinations of Quil $A$ cholesterol and dimethyldioctadecylammonium (DDA) bromide
}

\author{
Julia F. Ridpath \\ USDA-ARS, Julia.ridpath@ars.usda.gov \\ Paul Dominowski \\ Pfizer Animal Health \\ Ramasany Mannan \\ Pfizer Animal Health \\ Robert Yancey Jr. \\ Pfizer Animal Health \\ James A. Jackson \\ Pfizer Animal Health \\ See next page for additional authors
}

Follow this and additional works at: https://digitalcommons.unl.edu/usdaarsfacpub

Ridpath, Julia F.; Dominowski, Paul; Mannan, Ramasany; Yancey, Robert Jr.; Jackson, James A.; Taylor, Lucas; Mediratta, Sangita; Eversole, Robert; Mackenzie, Charles D.; and Neill, John D., "Evaluation of three experimental bovine viral diarrhea virus killed vaccines adjuvanted with combinations of Quil A cholesterol and dimethyldioctadecylammonium (DDA) bromide" (2010). Publications from USDA-ARS / UNL Faculty. 1277.

https://digitalcommons.unl.edu/usdaarsfacpub/1277

This Article is brought to you for free and open access by the U.S. Department of Agriculture: Agricultural Research Service, Lincoln, Nebraska at DigitalCommons@University of Nebraska - Lincoln. It has been accepted for inclusion in Publications from USDA-ARS / UNL Faculty by an authorized administrator of DigitalCommons@University of Nebraska - Lincoln. 


\section{Authors}

Julia F. Ridpath, Paul Dominowski, Ramasany Mannan, Robert Yancey Jr., James A. Jackson, Lucas Taylor, Sangita Mediratta, Robert Eversole, Charles D. Mackenzie, and John D. Neill 


\title{
Evaluation of three experimental bovine viral diarrhea virus killed vaccines adjuvanted with combinations of Quil A cholesterol and dimethyldioctadecylammonium (DDA) bromide
}

\author{
Julia F. Ridpath • Paul Dominowski • Ramasany Mannan • Robert Yancey Jr. • \\ James A. Jackson • Lucas Taylor • Sangita Mediratta • Robert Eversole • \\ Charles D. Mackenzie • John D. Neill
}

Accepted: 8 September 2010 / Published online: 28 September 2010

(C) US Government 2010

This article is a U.S. government work, and is not subject to copyright in the United States.

\begin{abstract}
Bovine viral diarrhea virus (BVDV) infections cause respiratory, reproductive, and enteric disease in cattle. Vaccination raises herd resistance and limits the spread of BVDV among cattle. Both killed and modified live vaccines against BVDV are available. While modified live vaccines elicit an immune response with a broader range and a longer duration of immunity, killed vaccines are considered to be safer. One way to improve the performance of killed vaccines is to develop new adjuvants. The goal of this research was evaluate new adjuvants, consisting of combinations of Quil A cholesterol and dimethyldioctadecylammonium (DDA) bromide, for use in killed vaccines. Responses to three novel killed vaccines, using combinations of Quil A and DDA as adjuvants, were compared to responses to a commercial modified live and a commercial killed vaccine. Vaccination response was monitored by measuring viral neutralizing antibodies (VN) levels and by response to challenge. All three novel vaccines were efficacious based on reduction in virus isolation, pyrexia, and depression. Compared to a commercial killed vaccine, the three novel vaccines elicited higher $\mathrm{VN}$ levels and reduced injection site inflammation.
\end{abstract}

Keywords Bovine viral diarrhea virus, adjuvant · Quil A cholesterol ·

Dimethyldioctadecylammonium bromide $\cdot$ Killed vaccine

\footnotetext{
J. F. Ridpath $(\bowtie) \cdot$ J. D. Neill

Ruminant Diseases and Immunology Research Unit, National Animal Disease Center, USDA, Agricultural Research Service, 1920 Dayton Avenue, P.O. Box 70, Ames, IA 50010, USA

e-mail: Julia.ridpath@ars.usda.gov

P. Dominowski $\cdot$ R. Mannan · R. Yancey Jr. J. A. Jackson · L. Taylor · S. Mediratta

Veterinary Medicine Research and Development, Pfizer Animal Health, Kalamazoo, MI, USA

R. Eversole

Biological Imaging Center, Western Michigan University, Kalamazoo, MI, USA

C. D. Mackenzie

College of Veterinary Medicine, Michigan State University, East Lansing, MI, USA
} 


\section{Introduction}

Reproductive and respiratory disease associated with infection with bovine viral diarrhea viruses (BVDV) result in significant economic losses for dairy and beef producers. The term BVDV refers to two distinct groups of viruses, BVDV1 and BVDV2, which are classified as two different species within the Pestivirus genus of the Flavivirus family (Ridpath 2008) Acute infections result in disease of varying severity, depending on the viral strain, the immune and reproductive status of the host, and the presence of secondary pathogens (Callan and Garry 2002; Evermann and Barrington 2005). Acute infections with BVDV, regardless of clinical presentation, are always accompanied by immune suppression due, at least in part, to the death of immune cells within lymph nodes and gut associated lymphoid tissue and reduction of numbers of circulating white blood cells (Liebler-Tenorio et al. 2002, 2004; Liebler-Tenorio et al. $2003 \mathrm{a}, \mathrm{b})$. The suppression of the immune system leaves infected animals vulnerable to secondary infections. In addition to acute infections, noncytopathic BVDV strains may establish life-long persistent infections. These persistent infections are the result of fetal exposure to BVDV before the development of the immune system (Brock et al. 2005). The PI animal is thought to be the major vector for introduction of BVDV into herds. There are two different goals for BVDV vaccination, one is to limit clinical disease (including immunosuppression) and viral shed following acute infections. The other is to prevent the fetal infection that leads to persistent infection.

Both modified-live virus (MLV) and killed vaccines are available for control of BVDV infections (Fulton 2005). MLV vaccines elicit a faster, longer lasting and broader response. However, post-vaccinal disease, particularly mucosal disease in PI animals, has been observed following vaccination with MLV vaccines. Killed vaccines are more stable and are safe for use in all animals. Killed vaccines are comprised of viral antigen (Ag) that has been inactivated by various methods, such as heat, chemicals or physical disruption, and can no longer replicate in vivo. Most commonly in inactivated BVDV vaccines, the $\mathrm{Ag}$ is enhanced with an adjuvant component, because the viral Ag is typically poorly immunogenic (Kwissa et al. 2007). Although considered to be the safer, killed vaccines may have incomplete or short-lived immune responses compared to MLV vaccines. Booster vaccinations are usually required to achieve protective immune responses. In addition, use of adjuvant may result in injection site reactions.

Adjuvant combinations (coadjuvantation) can potentially overcome some of the problems observed with killed vaccines (Fraser et al. 2007). The Q-series of adjuvants, used in this study, are comprised of multiple interchangeable molecules, including Quil A, cholesterol, and dimethyldioctadecylammonium (DDA) bromide. Quil A is an enriched fraction of a tri-terpenoid saponin derived from the bark of the South American tree Quillaja saponaria commonly used in veterinary vaccines (Kirk et al. 2004). When Quil A is combined with cholesterol (QAC) it forms helical, nanometer scale worm-like micelles (Mitra and Dungan 2001). DDA is a cationic, micelle-forming surfactant (Lincopan et al. 2007). In this study, three experimental vaccines, adjuvanted with Q-series adjuvants were compared to commercially available vaccines. Vaccination response was determined by measuring viral neutralizing antibodies (VN) levels before and after vaccination and by response to exposure to live BVDV following vaccination (challenge). The response to challenge was monitored by measuring changes in circulating white blood cells, basal temperature, and virus isolation. 


\section{Materials and methods}

\section{Experimental design}

Cattle were assigned to one of six vaccination protocols (Table 1). In protocol 1 (control protocol), cattle were injected subcutaneously, on days 0 and 21, with a sterile saline solution. In protocol 2 cattle were injected subcutaneously with a modified live virus vaccine on day 0 of the study (prepared by the protocol used for a commercial vaccine). In protocol 3 (killed vaccine prepared by protocol used for another commercial vaccine), cattle were injected subcutaneously on days 0 and 21 of the study. In protocols 4, 5, and 6, cattle were injected subcutaneously, on days 0 and 21 of the study, with experimental vaccines that were adjuvanted with different formulations of the Q-series adjuvants (see below).

Screening, housing and allotment of animals

Healthy, non-vaccinated beef calves (of mixed breed and gender), approximately 7 to 12 months of age (body weight range 272 to $442 \mathrm{~kg}$ ) were tested and confirmed negative for BVDV antigen based on immunohistochemistry performed on skin biopsies (University of Nebraska Veterinary Diagnostic Center, Lincoln, NE) (Brodersen 2004). Animals were screened for serum antibodies against BVDV by virus neutralization assay and only animals with VN titers $<1: 2$ were enrolled in the study (Ridpath et al. 2008).

Processing at arrival included administration of an injectable parasiticide (doramectin, Pfizer Animal Health, New York, NY) and a metaphylactic anti-microbial for BRD (tulathromycin, Pfizer Animal Health, New York, NY). Acclimatization began approximately 1 week before Day 0 . The animals had ad libitum access to commercial feed and to water from a municipal source.

This 56-day study used a generalized, randomized, incomplete block study design, with animals assigned to blocks of five animals each by body weight. The animal was the experimental unit. Within each block, treatments were randomly assigned to animals using a computer-generated plan. Animals were housed by vaccination protocol group from Day 0 to Day 21. On Day 35, the calves were randomly assigned to commingled pens and

Table 1 Vaccination protocols for 6 experimental groups

\begin{tabular}{|c|c|c|c|c|c|c|}
\hline Group & $\begin{array}{l}1 \\
\text { Negative } \\
\text { control }\end{array}$ & $\begin{array}{l}2 \\
\text { MLV } \\
\text { vaccine }\end{array}$ & $\begin{array}{l}3 \\
\text { Killed } \\
\text { vaccine }\end{array}$ & $\begin{array}{l}4 \\
\text { Experimental } \\
\text { vaccine }\end{array}$ & $\begin{array}{l}5 \\
\text { Experimental } \\
\text { vaccine }\end{array}$ & $\begin{array}{l}6 \\
\text { Experimental } \\
\text { vaccine }\end{array}$ \\
\hline Virus & None & Live virus & $\begin{array}{l}\text { Killed } \\
\text { virus }\end{array}$ & Killed virus & Killed virus & $\begin{array}{l}\text { Detergent } \\
\text { extracted virus }\end{array}$ \\
\hline Adjuvant & None & None & PreZent-A & $\begin{array}{l}\text { QAC } \\
\text { DDA } \\
\text { Carbopol }\end{array}$ & $\begin{array}{l}\text { QAC } \\
\text { DDA } \\
\text { Carbopol } \\
\text { R1005 }\end{array}$ & $\begin{array}{l}\text { QAC } \\
\text { DDA } \\
\text { Carbopol }\end{array}$ \\
\hline Inoculation & $\begin{array}{l}\text { Day } 0 \\
\text { Day } 21\end{array}$ & Day 0 & $\begin{array}{l}\text { Day } 0 \\
\text { Day } 21\end{array}$ & $\begin{array}{l}\text { Day } 0 \\
\text { Day } 21\end{array}$ & $\begin{array}{l}\text { Day } 0 \\
\text { Day } 21\end{array}$ & $\begin{array}{l}\text { Day } 0^{\mathrm{a}} \\
\text { Day } 21^{\mathrm{b}}\end{array}$ \\
\hline
\end{tabular}

\footnotetext{
${ }^{\text {a }}$ High titer extract

${ }^{\mathrm{b}}$ Low titer extract
} 
moved into isolation rooms before challenge with BVDV-2 on Day 42. Animals were housed by block with two blocks in each pen, six pens total. Blocks were randomly assigned to pens in each phase such that the weight variability within each pen was minimized. This design was balanced, 10 animals in each treatment group.

\section{Vaccination protocols}

Animals in group 1 received $0.9 \%$ sodium chloride sterile solution, on days 0 and 21 , and served as the control group. Animals in group 2 received a MLV BVDV-2 vaccine. The antigen concentration and formulation of this vaccine was the same virus and titer as that used in the production of the BoviShield Gold ${ }^{\circledR}$ vaccine line (Pfizer Animal Health, Kalamazo, MI). Briefly, this vaccine was a freeze-dried preparation of modified-live BVDV2 (propagated on an established bovine cell line) and was rehydrated with $0.9 \%$ sodium chloride sterile solution. This vaccine contained no adjuvant and was only administered once to this group on Day 0. Animals in group 3 received a killed virus BVDV-2 [inactivated with 5\% binary ethyleneimine (BEI); 44-72 $\mathrm{h}$ inactivation at 34-38 C] vaccine adjuvanted with Amphigen and QAC. This adjuvant is the same as the adjuvant in CattleMaster ${ }^{\circledR}$ Gold ${ }^{\mathrm{TM}}$, (PreZent-A ${ }^{\mathrm{TM}}$, Pfizer Animal Health). The BVDV2 antigen concentration and formulation of this vaccine was also the same as that of the CattleMaster Gold vaccine line (Pfizer Animal Health). Animals in groups 4, 5, and 6 received killedvirus vaccines containing novel adjuvants as listed in Table 1 . The concentration of BVDV $\mathrm{Ag}$ in the vaccines used for groups 4 and 5 was the same as the concentration present in the killed vaccine used for group $3(2,750 \mathrm{RU} / \mathrm{mL})$. The animals in group 6 received an experimental vaccine that differed in the method of antigen preparation but had the same adjuvant as the vaccine used for group 4. A detergent extraction method was used to prepare Ag enriched for BVDV proteins. The BVDV2 virus was extracted with sodium deoxycholate $\left(1.5 \mathrm{~h}\right.$ with mixing, $\left.25^{\circ} \mathrm{C}\right)$, clarified by centrifugation $(3,000 \times \mathrm{g}$ for $30 \mathrm{~min}$ at $25^{\circ} \mathrm{C}$ ), concentrated by dialysis using a $10 \mathrm{kD}$-cutoff ultrafiltration membrane, and sterilized using a 0.2-micron filter. Two different antigen concentrations were used in the two doses. The Ag concentration in the vaccine used for the first vaccine dose in group 6 was at a higher concentration $(>12,000 \mathrm{RU} / \mathrm{mL})$. The concentration in the second dose was $2,750 \mathrm{RU} / \mathrm{mL}$.

All treatments were administered subcutaneously in a single 2-mL dose on Days 0 and 21 , with the exception of Group 2 as noted above.

\section{Formulation of vaccines}

The following stock solutions were used in the formulation of the adjuvants used for protocols 4, 5, and 6. Quil A was dissolved in water to prepare a $50 \mathrm{mg} / \mathrm{mL}$ stock solution. Cholesterol (FabriChem Inc., Trumball, CT) was dissolved in ethanol to make a $17 \mathrm{mg} / \mathrm{mL}$ stock solution and the DDA was dissolved in ethanol to make an $18 \mathrm{mg} / \mathrm{mL}$ stock solution. Both of these stocks were filter sterilized using a $0.2-\mu$ filter. Carbopol $974 \mathrm{P} \mathrm{NF}$, a synthetic anionic polymer used as an adjuvant in commercial vaccines, was dissolved in water to prepare a $1.5 \%(w / v)$ stock solution and sterilized by autoclaving at $121{ }^{\circ} \mathrm{C}$ for $20 \mathrm{~min}$. The stock for Bay-R1005 was dissolved in phosphate buffer at a stock solution of $4.57 \mathrm{mg} / \mathrm{mL}$ and filter sterilized using a $0.2-\mu$ filter. Bay-R1005 [N-(2-Deoxy-2-Lleucyclamino-b-D-glucopyranosyl)-N-octadecylodecanoylamide hydroacetate] is an amphiphilic molecule that forms micelle in aqueous solution. It is a common adjuvant component in commercial vaccines. 
The adjuvant used for protocols 4 and 6 was identical. These protocols differed only in the viral antigen. The Group 4 and 6 formulations contained buffer, $50-\mu \mathrm{g} / \mathrm{mL}$ Quil A, 50$\mu \mathrm{g} / \mathrm{mL}$ cholesterol, $25-\mu \mathrm{g} / \mathrm{mL}$ DDA, and $0.075 \% \mathrm{w} / v$ of Carbopol. Antigen was combined with (add $80 \% v / v)$ buffer followed by addition of Quil A, cholesterol-ethanol, and DDAethanol using constant stirring. An appropriate volume of Carbopol was added to attain a final concentration of $0.075 \%$. The $\mathrm{pH}$ was adjusted to $\mathrm{pH} 7 \pm 0.2$ with $4 \mathrm{~N} \mathrm{NaOH}$. The viral antigen for protocols 4 and 5 were identical. The adjuvant for protocol 5 differed from that of protocols 4 and 6 in that R1005 also was added to a final concentration of $50 \mu \mathrm{g} / \mathrm{mL}$ for this formulation and the $\mathrm{pH}$ was not adjusted.

Antigen concentrations in vaccines were determined by ELISA. Readings were compared to a standard curve, which was prepared using an USDA accepted manufacturing reference standard. Antigen concentrations are stated in relative units (RU). The virus strain used in all vaccines was strain 53637. This strain belongs to the BVDV2a subgenotype.

\section{BVDV-2 challenge}

On Day 42 all the animals were challenged with a noncytopathic BVDV-2a (strain 24515) at a concentration $5.4 \log ^{10} \mathrm{TCID}_{50}$ per $5-\mathrm{mL}$ dose. The challenge inoculum was delivered intranasally, approximately $2.5 \mathrm{~mL}$ per nostril, using a compressed gas nebulizer. Dose titration assays were conducted on pre- and post-challenge samples as described previously. (Cortese et al. 1998)

Please note that two different BVDV2a strains were used in vaccine formulations (strain 53637) and challenge studies (strain 224515). Based on phylogenetic analysis performed using sequences from the $5^{\prime}$ untranslated region, these two strains belong to the same subgenotype, but are not identical.

\section{Blood testing}

Blood samples were collected on days $0,21,41$, and 56. Serum from blood samples was harvested, divided into aliquots, and submitted for testing or stored frozen at $<-20^{\circ} \mathrm{C}$. Viral neutralizing titers in collected sera were determined against three BVDV1a strains (BVDV1aSinger, BVDV1a-5960, and BVDV1a-NADL), three BVDV1b strains (BVDV1b-TGAC, BVDV1b-Illc, and BVDV1b-2110), and three BVDV2a strains (BVDV2a-296c, BVDV2a-ND 8799, and BVDV2a-MsSt T-4529) as described previously (Ridpath et al. 2010). Buffy coat samples were harvested from whole blood collected on days 40 through 56 . These samples were assayed for replicating BVDV by tissue culture isolation followed by Ab staining (Cortese et al. 1998). Total circulating white blood cell counts (WBC) and platelet counts were determined as described previously (Ridpath et al. 2007).

Health observations

On Days -1 to 39, animals were observed daily for general health. After the BVDV-2 challenge, the animals were monitored each morning for clinical signs of BVDV disease (depression, nasal discharge, and respiratory distress) and each afternoon for general health. For $1 \mathrm{~h}$ after each vaccination animals were observed for systemic reactions, such as anaphylaxis, depression, reduced coordination, increased respiration, diarrhea, inappetence, or trembling. Injection-site reactions were observed on Days $0,1,2,3,7$, and 21 for the first vaccination, and on Days 21, 22, 23, 24, 28, and 42 for the second vaccination. All palpable injection-site reactions were measured (length $\times$ depth $\times$ width) and the size 
recorded. Rectal temperatures were recorded from day -1 to day 56 . Fever was defined as a rectal temperature $>40.3^{\circ} \mathrm{C}\left(104.5^{\circ} \mathrm{F}\right)$. Leukopenia was defined as a $40 \%$ decrease in $\mathrm{WBC}$ counts compared to pre-challenge WBC count means.

Data summary and analyses

In the challenge phase, rectal temperatures, serology data, viremia data, WBC counts, and platelet counts were analyzed with a general linear repeated measures mixed model with fixed effects (treatment, time-point, and treatment by time-point interaction) and random effects (pen, animal within treatment and pen, which was the animal term, and the residual). Linear combinations of the parameter estimates were used in a priori contrasts after testing for a significant $(P \leq 0.05)$ treatment or treatment by time-point effect. Comparisons were made between treatments at each time-point. Back transformed least squares means (from serology), their standard errors and their $90 \%$ confidence intervals were calculated from least squares parameter estimates obtained from the analyses.

\section{Results}

Serum neutralizing titers prior to challenge

All animals were seronegative to BVDV-1 and BVDV 2 before vaccination (Day -1). Figure 1 presents SN titers on Day 41 (41 days past first vaccination, 20 days after the second vaccination, and 1 day before challenge). On day 41, group 1 (control animals) were seronegative to BVDV-1 and BVDV-2. All animals in Groups 3 through 6, and eight of 10 animals in Group 2, had BVDV-2 titers of at least 1:8 on Day 41. The mean BVDV-1 and

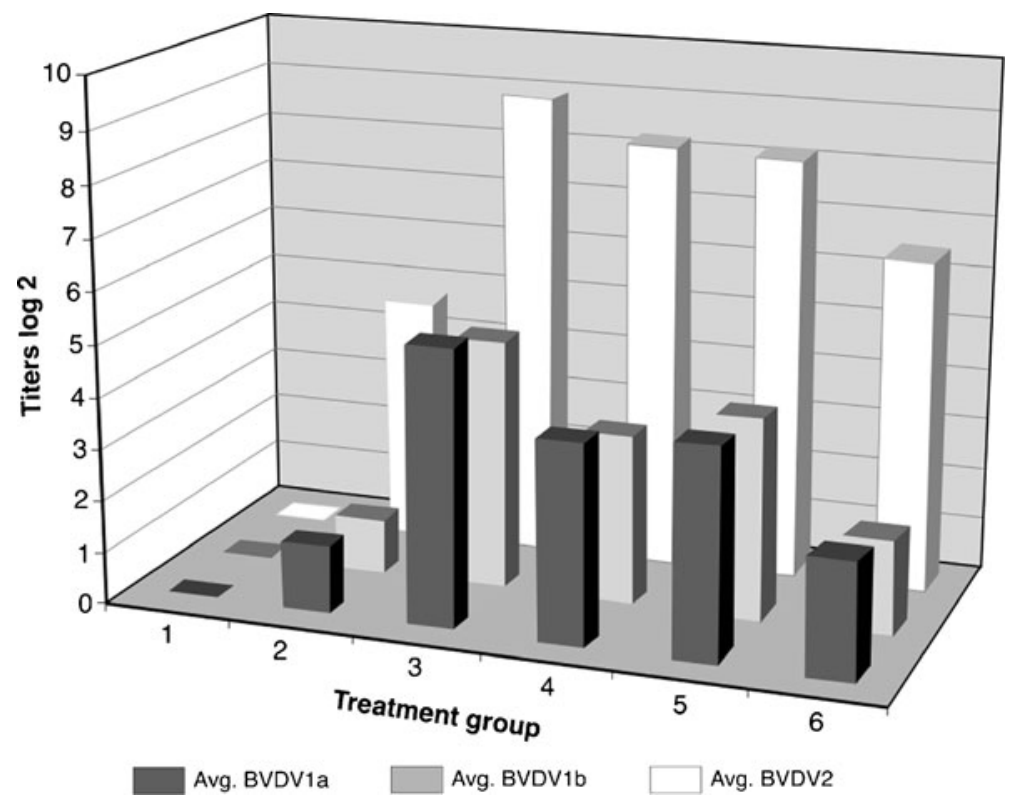

Fig. 1 Average neutralizing titers of animals from different treatment groups against strains of BVDV1a, BVDV1b, and BVDV2 
BVDV-2 titers of Group 2 was statistically significantly $(P \leq 0.0015)$ smaller than those of Groups 3, 4, 5, and 6. The mean BVDV-2 titer of Group 6 was statistically significantly $(P \leq 0.0335)$ smaller than those of Groups 3,4 , and 5 . The mean BVDV-1 titer of Group 4 was statistically significantly $(P \leq 0.0357)$ smaller than the mean of Group 3 .

\section{Response to challenge}

Virus isolation was performed on samples collected between Days 41 and 56 (Table 2). Virus positive samples were detected longer and more frequently from animals in group 1 than animals from groups 2 through 6 . A statistically significant difference $(P \leq 0.0031)$ was found between the number of positive animals in Group 1 (10 of 10) compared to the numbers of positive animals (one of 10 to three of 10) for all other treatment groups. Results for Groups 2 through 6 did not differ significantly from each other.

Figure 2 graphs rectal temperatures throughout the study. Slight increases in mean rectal temperatures of generally $<0.56^{\circ} \mathrm{C}\left(1^{\circ} \mathrm{F}\right)$ from pre-vaccination levels were observed following the primary and booster vaccinations in all treatment groups. Following challenge, the mean rectal temperature of Group 1 first rose to $>39.4^{\circ} \mathrm{C}\left(103.0^{\circ} \mathrm{F}\right)$ on Day 50 and peaked on Day 52 at $40.1^{\circ} \mathrm{C}\left(104.2^{\circ} \mathrm{F}\right)$. The mean rectal temperatures for Groups 2, 3, and 5 never exceeded $39.4^{\circ} \mathrm{C}\left(102.9^{\circ} \mathrm{F}\right)$ on any day. For Group 4 , a mean temperature greater than $39.4^{\circ} \mathrm{C}\left(103.0^{\circ}\right.$ F) was only recorded on 1 day (day 51). The mean temperature for Group 6 peaked at $39.6^{\circ} \mathrm{C}$ $\left(103.3^{\circ} \mathrm{F}\right)$ on Day 52. Using the pre-determined, post-challenge fever criterion listed in 9 CFR $\S 113.215$, eight of 10 animals in Group 1, no animals in Groups 2 and 3, one of 10 animals in Groups 4 and 5, and two of 10 animals in Group 6 were febrile. The number of febrile animals in Group 1 was statistically significantly larger $(P \leq 0.0190)$ than those of all other groups. The differences observed between mean daily temperatures for groups 2 through 6 were not statistically significant.

Figure 3 plots the number of animals with leukopenia by study day. For Group 1, there was at least one animal with leukopenia ( $>40 \%$ decrease in WBC from baseline) every day from Days 46 through 56. In contrast, there were never any leukopenic animals in Group 2. For Groups 3, 4, 5, and 6, leukopenic animals were present on Days 47 through 50, 47 through 49, 47 through 50, and 47 through 51, respectively. All animals in Group 1, eight of 10 in Group 6, one of 10 in Group 3, and three of 10 in both Groups 4 and 5 experienced leukopenia, none ( 0 of 10$)$ of the animals in Group 2 were leukopenic. There were no significant differences $(P>0.05)$ in platelet counts among any of the treatment groups on any study day.

Table 2 Results of virus isolation

\begin{tabular}{llllll}
\hline $\begin{array}{l}\text { Group } \\
\text { sample }\end{array}$ & $\begin{array}{l}\text { \# of animals with at } \\
\text { least 1 VI pos }\end{array}$ & $\begin{array}{l}\text { \# of days VI pos } \\
\text { samples detect in } \\
\text { group }\end{array}$ & $\begin{array}{l}\text { Greatest \# of animals VI } \\
\text { pos on any one sampling } \\
\text { date }\end{array}$ & $\begin{array}{l}\text { Day of first } \\
\text { VI pos } \\
\text { sample }\end{array}$ & $\begin{array}{l}\text { Day of } \\
\text { last VI } \\
\text { pos }\end{array}$ \\
\hline 1 & 10 & 11 & 10 & 46 & 56 \\
2 & 3 & 4 & 1 & 47 & 51 \\
3 & 1 & 2 & 1 & 47 & 48 \\
4 & 2 & 3 & 1 & 47 & 50 \\
5 & 2 & 2 & 1 & 47 & 49 \\
6 & 2 & 4 & 2 & 49 & 52 \\
\hline
\end{tabular}




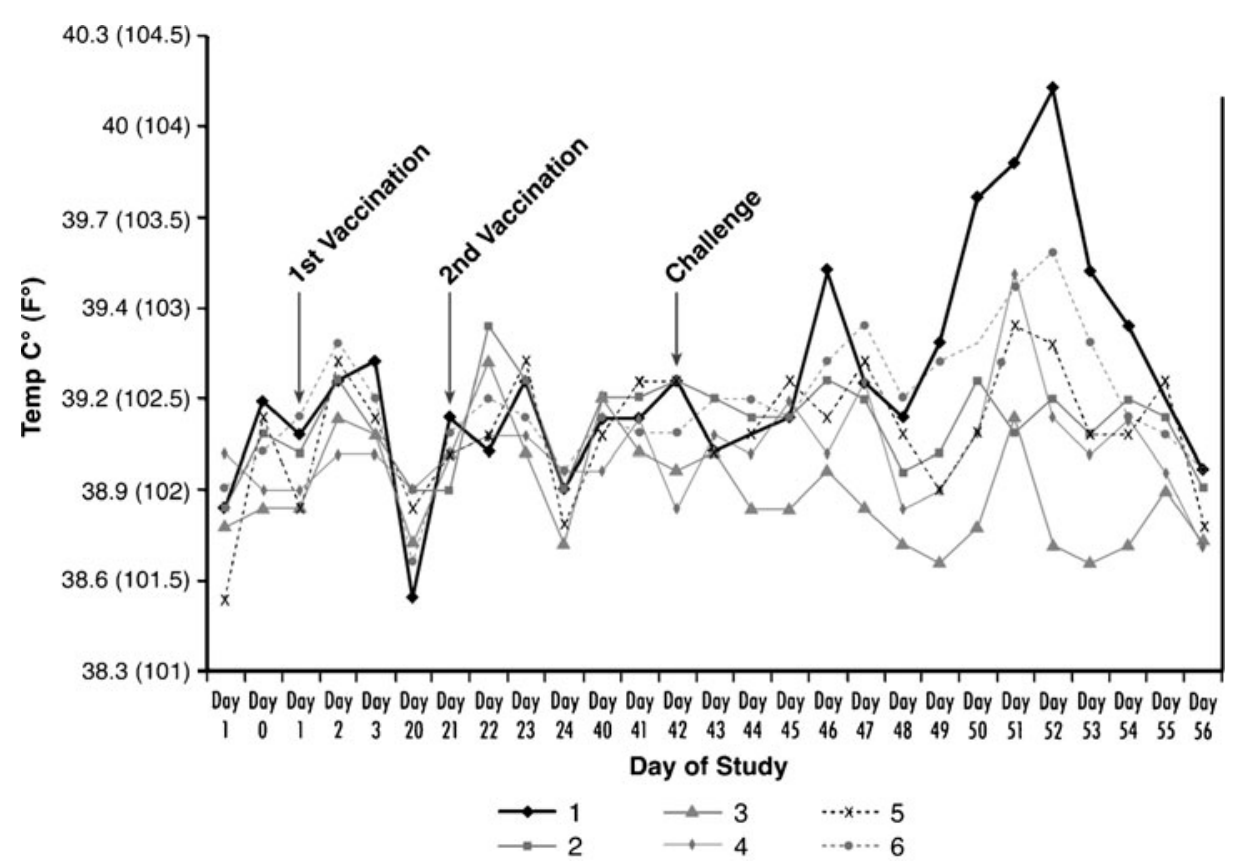

Fig. 2 Average daily temperature of animals from each treatment group

There were no statistically significant differences $(P>0.05)$ among groups in the occurrence of depression, nasal discharge, or increased respiratory effort. One animal in Group 4 was removed from the study on Day 53 due to a severely swollen left shoulder that became infected. The injury was not related to vaccination.

Injection-site reactions

The number of animals with observable infection site reactions and the size of the largest reaction are detailed in Table 3. The largest reactions occurred in Group 3 on the days following vaccinations, with reaction sites measuring from 0 to $133.52 \mathrm{~mL}$ on Day 1 and 0 to $27.44 \mathrm{~mL}$ on Day 22. Small residual reactions were still palpable in Groups 1, 2, 3, and 6 on Day 42. Reactions in all groups resolved rapidly within $48 \mathrm{~h}$ of vaccination. The volumes of reactions for Group 3 were statistically significantly $(P \leq 0.0497)$ larger than those of Group 1 on Days 22, 23, and 24, and Group 2 on Days 22 through 24 and 28, and larger than those of Groups 4, 5, and 6 on Days 22 through 24.

\section{Discussion}

Serological response as determined by development of neutralizing antibodies and clinical presentation following challenge exposure are the most commonly used methods to gauge the protective response induced by BVDV vaccines (Kelling 2004). In this study, two doses of any of the killed vaccines resulted in higher neutralizing titers than one dose of the MLV vaccine. The highest titers were observed after use of the conventional (prepared according to protocol used for a commercially available vaccine) killed vaccine. Titers in all animals 


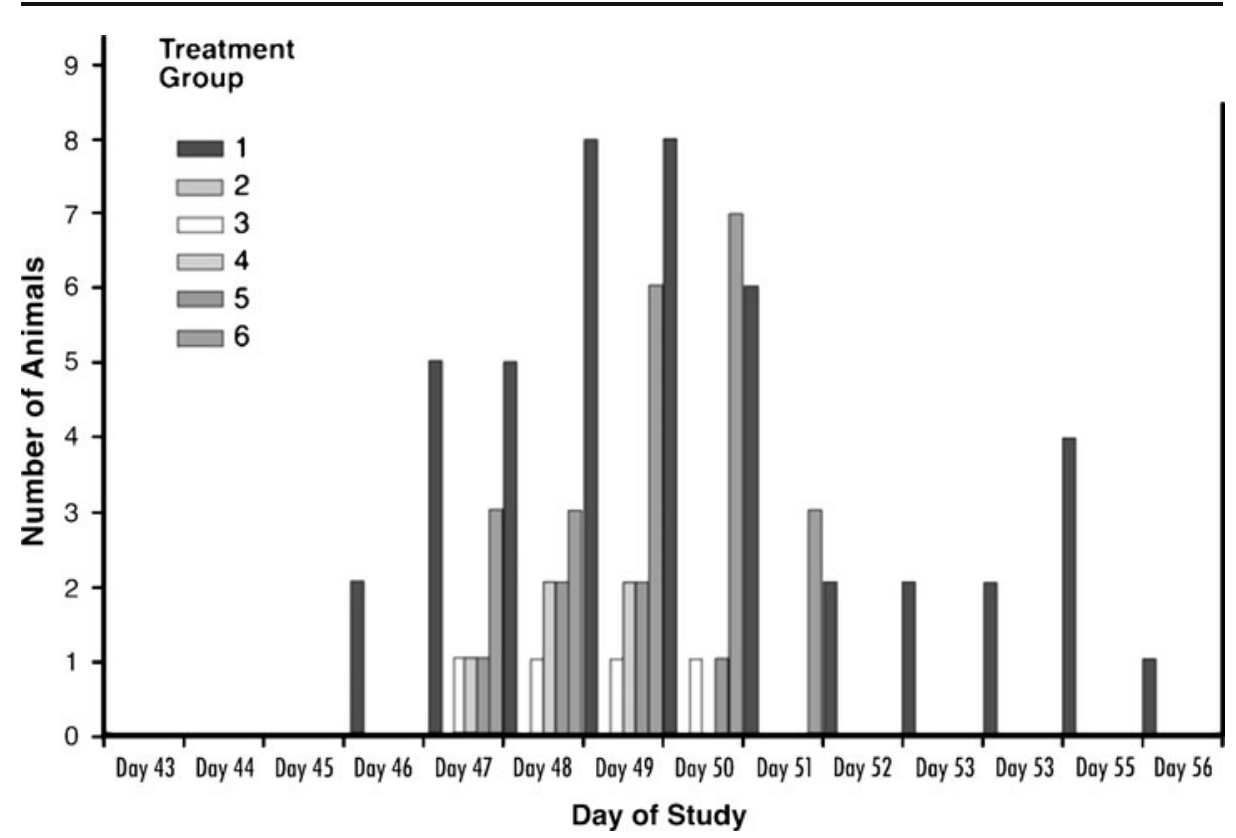

Fig. 3 Number of leukopenic animals from each treatment group following challenge on day 42

were higher against BVDV2 strains compared to BVDV1a or BVDV1b strains reflecting the inclusion of BVDV2, but not BVDV1a or BVDV1b, antigen in the vaccines.

Animal receiving mock vaccinations did not develop measurable titers of neutralizing antibodies prior to challenge and were not protected from viral replication or clinical disease following challenge exposure as determined by virus isolation, pyrexia, and leukopenia. Virus was isolated from at least one animal in all vaccinated groups but less frequently than from animals in the non-vaccinated group and for a shorter duration of time. Among the vaccinated groups, virus was isolated from more animals in Group 2 (MLV vaccine, 3 animals) compared to Groups 3, 4, 5, and 6 (killed virus vaccines, 1-2 animals). However, there was no significant difference in the length of viral shed between animals vaccinated with MLV vaccine and animals vaccinated with killed vaccines.

More animals, vaccinated with the three experimental killed vaccines, experienced pyrexia compared to animals vaccinated with the conventional killed and MLV vaccines. However, only 1-2 animals were affected and the pyrexia was low grade and of short duration compared to non-vaccinated animals. Similarly more animals, vaccinated with the three experimental killed vaccines, experienced leukopenia compared to the animals vaccinated with the conventional killed and MLV vaccines. The number of leukopenic animals was significantly higher in group 6 compared to the other vaccinated groups and was only slightly lower than the non-vaccinated group. The duration of leukopenia was similar in groups 3, 4, 5, and 6 (both conventional and experimental killed vaccines) and was significantly shorter than the duration of leukopenia in the non-vaccinated group.

Injection site reactions were more pronounced in animals vaccinated with the conventional killed vaccine. The function of adjuvants is to augment the effects of a vaccine by stimulating the immune system to respond more strongly to the vaccine antigen. While the exact mode of action of most adjuvants is unknown it is thought that they work by mimicking specific sets of evolutionarily conserved pathogen-associated molecular 


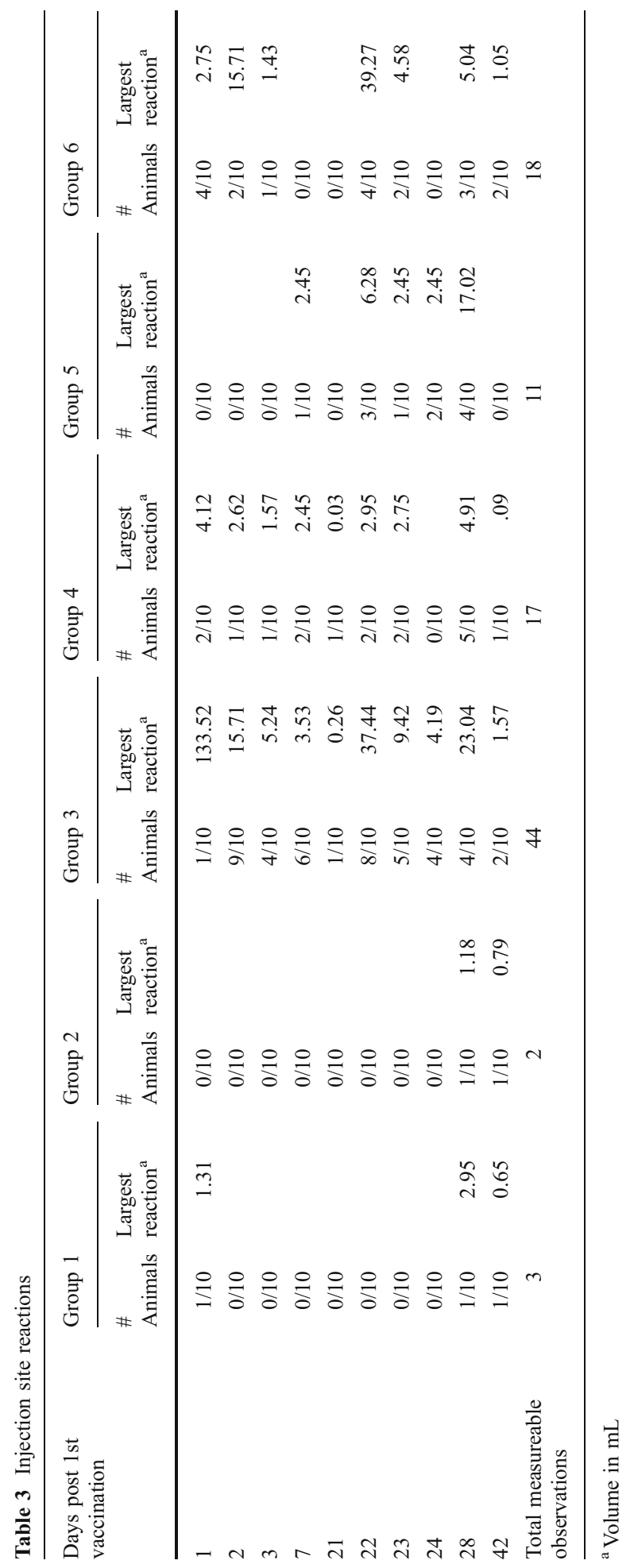


patterns (PAMPs). The immune system recognizes PAMPs as non self molecules and activates the innate immune system. Activation of the innate immune system by adjuvants results in a greater immune response. However, over stimulation or stimulation that elicits an inappropriate response results in adverse reactions that expend physiological resources but do not contribute to enhanced protection. An example of an inappropriate response is injection site reactions. Swelling at the injection site increases animal discomfort and may reduce carcass quality. These reactions result from a nonspecific irritation of the immune system and do not contribute to improved protection against specific vaccine antigen. The perfect adjuvant would increase the strength of the vaccine antigen specific response (as reflected by development of neutralizing antibodies) and have very limited nonspecific immune irritation response (as reflected by little or no injection site reactions).

While eliciting the lowest titers of serum neutralizing antibodies, the MLV vaccine exhibited the highest level of protection based on prevention of pyrexia and leukopenia. Higher protection in spite of lower levels of neutralizing antibodies may be related to the stimulation of $\mathrm{T}$ cell responses in addition to $\mathrm{B}$ cell responses. It is interesting to note that while preventing clinical presentation of disease, the MLV vaccine was no more effective than killed vaccines in preventing viremia. The experimental vaccine used in Group 6, while giving some protection, was the least effective of the vaccines. This suggests that the process used for enriching for viral proteins, may have eliminated or reduced antigens that are important to the development of protective immunity.

Protection elicited by the experimental killed vaccines used in groups 4 and 5 was similar or only slightly reduced from that of the conventional killed vaccine. These two experimental vaccines demonstrated an advantage over the conventional killed vaccine in that they had significantly reduced injection site reactions. This suggests that these adjuvants maintained the protective immune response while ameliorating non-protective inflammatory responses. Vaccination always carries with it a physiological cost. Production of an immune response requires energy and can result in animal discomfort. It is desirable to produce the greatest protective response at the lowest physiological expense. One way to decrease the physiological cost is to reduce non-protective responses. Non-protective inflammatory responses in particular contribute to physiological cost, increase animal discomfort and may decrease carcass value. The advantage of these vaccines would lie in their ability to produce a protective immune response as a reduced physiological cost.

Acknowledgments The authors thank Kathy Fulk, David Michaels and Patricia Federico for excellent technical support and Michael Marti and Sandy Johnson for support in manuscipt preparation.

This research was supported in part by a Trust agreement (3625-32000-087-04T) between Pfizer Animal Health and the NADC.

\section{References}

Brock KV, Grooms DL, Givens MD (2005) Reproductive disease and persistent infections. In: Goyal SM, Ridpath JF (eds) Bovine viral diarrhea virus: diagnossis, management and control. Blackwell, Ames, pp 145-156

Brodersen BW (2004) Immunohistochemistry used as a screening method for persistent bovine viral diarrhea virus infection. Vet Clin North Am Food Anim Pract 20:85-93

Callan RJ, Garry FB (2002) Biosecurity and bovine respiratory disease. Vet Clin North Am Food Anim Pract 18:57-77

Cortese VS, Grooms DL, Ellis J, Bolin SR, Ridpath JF, Brock KV (1998) Protection of pregnant cattle and their fetuses against infection with bovine viral diarrhea virus type 1 by use of a modified-live virus vaccine. Am J Vet Res 59:1409-1413 
Evermann JF, Barrington GM (2005) Clinical features. In: Goyal SM, Ridpath JF (eds) Bovine viral diarrhea virus: diagnosis. management and control. Blackwell, Ames, pp 105-120

Fraser CK, Diener KR, Brown MP, Hayball JD (2007) Improving vaccines by incorporating immunological coadjuvants. Expert Rev Vaccines 6:559-578

Fulton RW (2005) Vaccines. In: Goyal SM, Ridpath JF (eds) Bovine viral diarrhea virus: diagnosis, management and control. Blackwell, Ames, pp 209-222

Kelling CL (2004) Evolution of bovine viral diarrhea virus vaccines. Vet Clin North Am Food Anim Pract 20:115-129

Kirk DD, Rempel R, Pinkhasov J, Walmsley AM (2004) Application of Quillaja saponaria extracts as oral adjuvants for plant-made vaccines. Expert Opin Biol Ther 4:947-958

Kwissa M, Kasturi SP, Pulendran B (2007) The science of adjuvants. Expert Rev Vaccines 6:673-684

Liebler-Tenorio EM, Ridpath JE, Neill JD (2002) Distribution of viral antigen and development of lesions after experimental infection with highly virulent bovine viral diarrhea virus type 2 in calves. Am J Vet Res 63:1575-1584

Liebler-Tenorio EM, Ridpath JF, Neill JD (2003a) Distribution of viral antigen and development of lesions after experimental infection of calves with a BVDV 2 strain of low virulence. J Vet Diagn Invest 15:221-232

Liebler-Tenorio EM, Ridpath JF, Neill JD (2003b) Lesions and tissue distribution of viral antigen in severe acute versus subclinical acute infection with BVDV2. Biologicals 31:119-122

Liebler-Tenorio EM, Ridpath JE, Neill JD (2004) Distribution of viral antigen and tissue lesions in persistent and acute infection with the homologous strain of noncytopathic bovine viral diarrhea virus. J Vet Diagn Invest 16:388-396

Lincopan N, Espindola NM, Vaz AJ, Carmona-Ribeiro AM (2007) Cationic supported lipid bilayers for antigen presentation. Int J Pharm 340:216-222

Mitra S, Dungan SR (2001) Cholesterol solubilization in aqueous micellar solutions of quillaja saponin, bile salts, or nonionic surfactants. J Agric Food Chem 49:384-394

Ridpath JF (2008) Bovine viral diarrhea virus. In: Mahy BWJ, Regenmortel MHV (eds) Encyclopedia of virology. Elsevier, Oxford, pp 374-380

Ridpath JF, Neill JD, Peterhans E (2007) Impact of variation in acute virulence of BVDV1 strains on design of better vaccine efficacy challenge models. Vaccine 25:8058-8066

Ridpath JF, Driskell EA, Chase CC, Neill JD, Palmer MV, Brodersen BW (2008) Reproductive tract disease associated with inoculation of pregnant white-tailed deer with bovine viral diarrhea virus. Am J Vet Res 69:1630-1636

Ridpath JF, Fulton RW, Kirkland PD, Neill JD (2010) Prevalence and antigenic differences observed between Bovine viral diarrhea virus subgenotypes isolated from cattle in Australia and feedlots in the southwestern United States. J Vet Diagn Invest 22:184-191

\section{Disclaimer}

Mention of trade names or commercial products in this article is solely for the purpose of providing specific information and does not imply recommendation or endorsement by the U.S. Department of Agriculture. 